\title{
Civicae
}

\section{Características comportamentais do empreendedorismo feminino no Vale do Jequitinhonha}

Este estudo buscou identificar os perfis empreendedores femininos localizados no Vale do Jequitinhonha, norte do Estado de Minas Gerais e relacioná-los com as teorias de comportamentos empreendedoras propostas por Baker et al. (2005) e McClelland (1985). A pesquisa de cunho exploratório é quantitativa e se optou pelo questionário como instrumento para coleta de dados. Os resultados da pesquisa apontaram ser possível relacionar as teorias propostas com os perfis das empreendedoras pesquisadas. As respondentes desta pesquisa têm entendimento acerca das características comportamentais a partir de suas experiências. $O$ entendimento das empreendedoras, em relação às teorias de Baker e Nelson, confirma-se a partir de características de análise do mercado que o seu negócio está inserido. As teorias de McClelland permitiram que as empreendedoras identificassem inúmeras características individuais presentes no seu modo de gestão.

Palavras-chave: Empreendedorismo feminino; Características comportamentais; Mercado.

\section{Behavioral characteristics of female entrepreneurship in Vale do Jequitinhonha}

This paper sought to identify the female entrepreneur profiles located in the Vale do Jequitinhonha, north of the State of Minas Gerais and to relate them to the theories of entrepreneurial behaviors proposed by Baker et al. (2005) and McClelland (1985). Exploratory research is quantitative and the questionnaire was chosen as an instrument for data collection. The results of the research pointed out that it is possible to relate the theories proposed with the profiles of the researched entrepreneurs. The respondents in this research have an understanding of the behavioral characteristics from their experiences. The entrepreneurs' understanding of Baker and Nelson's theories is confirmed by the characteristics of market analysis that their business is inserted. McClelland's theories allowed women entrepreneurs to identify numerous individual characteristics present in their management mode.

Keywords: Female entrepreneurship; Behavioral characteristics; Market.

Topic: Cultura, Gênero e Subjetividade

Reviewed anonymously in the process of blind peer.
Received: 12/05/2019

Approved: 08/09/2019
Kenia Lima Ferreira

Instituto Federal do Norte de Minas Gerais, Brasil

http://lattes.cnpq.br/7154579576337982

kenialimaferreira@hotmail.com

André Geraldo da Costa Coelho

Instituto Federal de Minas Gerais, Brasil

http://lattes.cnpq.br/9562191570068458

http://orcid.org/0000-0001-7428-3953

andre.coelho@ifmg.edu.br

Maria das Graças da Silva Costa Coelho (io

Centro Federal de Minas Gerais, Brasil

http://lattes.cnpq.br/0094690472932481

http://orcid.org/0000-0002-1855-5392

mariacoelho@cefetmg.br
Sheldon William Silva (iD)

Instituto Federal de Minas Gerais, Brasil

http://lattes.cnpq.br/5691436224279198

http://orcid.org/0000-0002-2473-5728

sheldonwilliamsilva@gmail.com

João Francisco Sarno Carvalho (D)

Instituto Federal do Norte de Minas Gerais, Brasil

http://lattes.cnpq.br/5217806842201673

http://orcid.org/0000-0001-8815-4773

joao.carvalho@ifnmg.edu.br
Referencing this:

FERREIRA, K. L.; COELHO, A. G. C.; COELHO, M. G. S.; SILVA, S. W.; CARVALHO, J. F. S.. Características comportamentais do empreendedorismo feminino no Vale do Jequitinhonha. Justitia Liber, v.1, n.2, p.12-23, 2019. DOI: http://doi.org/10.6008/CBPC2674$\underline{6646.2019 .002 .0002}$ 


\section{INTRODUÇÃO}

A atividade empreendedora é considerada o ramo que mais cresce no Brasil. De acordo com o relatório de pesquisas realizadas pelo Global Entrepreneurship Monitor - GEM (2017), o empreendedorismo continua sendo um assunto muito abordado em todo o mundo, sendo que no Brasil tem ganhado maior destaque nos últimos anos. Ademais, devido aos grandes avanços de pesquisas e iniciativas de diversos órgãos que têm a intenção de impulsionar e auxiliar a atividade empreendedora, criou-se um contexto favorável para se compreender os caminhos do perfil empreendedor a nível nacional.

Nesse contexto de inovações, destaca-se um novo perfil empreendedor, o feminino. Existem várias atividades de negócios nos mais diversificados ramos que são marcados pela participação crescente das mulheres. Percebe-se que as mulheres vêm se destacando por estarem cada vez mais envolvidas com o ramo empresarial e por estarem sempre em busca de novos desafios, principalmente quando o assunto envolve $o$ empreendedorismo (GOUVÊA et al., 2013). De acordo com as concepções de Gimenez et al. (2016), o perfil feminino, tem se adequado as mudanças e desenvolvendo características natas de um empreendedor, sendo estas notadas pelo seu desempenho, crescimento e respeito profissional, voltados para o aumento de contatos e o conhecimento gerencial.

A pesquisa de Gouvêa et al. (2013) enfatizam que uma empreendedora possui características e habilidades necessárias que são indispensáveis ao mercado fortemente competitivo, e em contínuo processo de inovação e mudanças, em um campo de recursos escassos. Essas características são enfatizadas por McClelland (1985), a partir da associação das características comportamentais empreendedoras e as personalidades de empreendedores bem-sucedidos. Ao buscar alternativas para aprimorar o seu empreendimento, o empreendedor busca por possíveis soluções para os problemas encontrados no ambiente de negócios. Entre os métodos que podem auxiliar o empreendedor na busca por soluções para os problemas encontrados no ambiente dos negócios se pode destacar o método Bricolagem, que tem como principal característica o uso de recursos escassos. Baker et al. (2005) são considerados os criadores desse método, caracterizado pela inserção em determinado negócio por meio da utilização de recursos acessíveis que muitas vezes são considerados descartáveis, transformando-os em novas oportunidades.

Este estudo tem como objetivo identificar perfis empreendedores femininos, localizados na mesorregião do Vale do Jequitinhonha, de modo a buscar relacioná-los com as características comportamentais empreendedoras de Baker e Nelson e McClelland. O estudo ainda propõe apontar as formas de como o método Bricolagem pode auxiliar as empreendedoras a gerir melhor o seu negócio, mediante os recursos escassos e ao mercado competitivo e analisar as vantagens e desvantagens do método Bricolagem quanto à sua utilidade. Procurou-se identificar quais as características que estavam presentes na amostra coletada nas cidades de Coronel Murta e Araçuaí, situadas na mesorregião do Vale do Jequitinhonha, norte do Estado de Minas Gerais.

Justifica-se a importância da pesquisa mediante a escassez de estudos que analisam o empreendedorismo feminino ao buscar formas de compreender as características comportamentais 
empreendedoras. Destaca-se ainda o contexto da região pesquisada, que possui um alto índice de empreendedoras que estão em processo de aprendizado para operar seu empreendimento no seu ramo de atuação e aperfeiçoá-lo, independente do cenário econômico enfrentado no momento. Nesse sentido, a pesquisa apresenta como fundamentação teórica um panorama sobre o empreendedorismo no Brasil, aprofundando seu contexto ao gênero feminino e suas características. Discute-se ainda o modelo de bricolagem e as características empreendedoras propostas por Baker et al. (2005) e McClelland (1985).

\section{REVISÃO TEÓRICA}

Uma pessoa que tem a pretensão de iniciar um negócio desempenha quatro papéis para administrar: empresário, executivo, empregado e empreendedor. O empreendedor, mediante esta análise administrativa é aquele que empreende um negócio, assumindo todos os riscos sejam eles comerciais, legais e até mesmo pessoais. Tem uma visão ampla do negócio e sem medir esforços concretiza sua ideia tornando-a real (ZEN et al., 2008). Nesse sentido, quando a questão está relacionada com o empreendedorismo, logo vem em mente a criação ou existência de uma empresa. Daft (2015) enfatiza esse entendimento e ressalta que o empreendedorismo é o desenvolvimento de um negócio onde há riscos, mas com disciplina e meios fundamentais o empreendedor também tem as compensações elencadas ao negócio. Para tanto, compreender o termo empreendedorismo se faz necessário abarcar um levantamento histórico, apresentando algumas abordagens em relação ao tema, conforme exposto no Quadro 1.

Quadro 1: Desenvolvimento do pensamento empreendedor.

\begin{tabular}{|l|l|}
\hline $\begin{array}{l}\text { Era Econômica } \\
\mathbf{( 1 8 7 0 - 1 9 4 0 )}\end{array}$ & $\begin{array}{l}\text { Marcada pelo fascínio dos economistas pelo empreendedorismo onde surge a teoria econômica } \\
\text { integrada à mudança e inovação. }\end{array}$ \\
\hline $\begin{array}{l}\text { Era das Ciências } \\
\text { Sociais (1940 - 1970) }\end{array}$ & $\begin{array}{l}\text { Apontada como o período em que estudiosos adentravam nas áreas de psicologia e ciências sociais. } \\
\text { Estes tinham seus interesses voltados no empreendedor, e iniciaram uma análise sobre suas práticas e } \\
\text { traços de personalidade. }\end{array}$ \\
\hline $\begin{array}{l}\text { Era dos Estudos de } \\
\text { Gestão (1970- atual) }\end{array}$ & $\begin{array}{l}\text { Ainda se encontra em evolução e é representada por transições econômicas, políticas e tecnológicas, } \\
\text { sendo o empreendedorismo ainda dominante na sociedade. }\end{array}$ \\
\hline
\end{tabular}

Fonte: Verga et al. (2014).

Melo (2014), cita os principais autores que foram responsáveis por formular o conceito sobre empreendedorismo: Richard Cantillon, Jean-Baptist Say e Joseph Alois Schumpeter. Assim, cabe ressaltar alguns teóricos importantes, como Cantillon (1755), que conservava um pensamento sobre o empreendedor como sendo uma pessoa que assume riscos. Say (1815) considerava o empreendedor como indivíduo que cria valor. Schumpeter (1947), que foi responsável pela denominação da inovação, considerou o empreendedor como fator importante e influenciador da economia. De acordo com as pesquisas de Almeida et al. (2017), o tema empreendedorismo se intensificou no Brasil no começo do ano de 2000 com resultado de análises realizadas por instituições de ensino superior e pós-graduação. Essas análises tiveram base devido ao crescimento de pequenos negócios que ocorriam no Brasil. Segundo o relatório do GEM (2017), as análises sobre capacidades de eficiência e inovação apontam o Brasil como oitavo lugar no ranking mundial, frente aos 31 países estudados. Ainda segundo o relatório, o Brasil possui 21\% de empreendimentos que assumem capacidades de eficiência e inovação, de modo que esta porcentagem corresponde a 26 milhões de 
brasileiros que estão envolvidos com algum tipo de atividade empreendedora e estão no mercado em um período inferior a 42 meses.

Ao analisar as características comportamentais de empreendedores, percebe-se que alguns desses empreendedores iniciaram suas atividades por necessidade, outros, encararam a situação como uma oportunidade que o mercado estava propondo. O empreender por necessidade busca por alternativas relacionadas à sobrevivência, encorajados pela tensão do desemprego. Já o empreendedor por oportunidade advém do desejo de alguma realização pessoal, na qual a situação atual não mais o atende (VALE et al., 2014). Nesse sentido, para realçar a importância do debate do gênero no empreendedorismo brasileiro é indispensável voltar ao passado e relembrar a trajetória da mulher para conquistar seu espaço na sociedade.

A introdução da mulher no mercado de trabalho foi lenta, e ainda existem obstáculos para serem superados. O século XXI ainda traz consigo um processo sólido de transformações que acontece em todas as estruturas sociais e culturais. Essas transformações estão acontecendo de forma rápida, atingindo diretamente os padrões comportamentais, passando pelas instituições, meio acadêmico e principalmente, nas organizações profissionais (RODRIGUES et al., 2016).

O GEM (2017) salientou em seu último informe publicado que o empreendedorismo feminino vem ganhando espaço em diversas áreas profissionais. De acordo com o informe, ainda persiste uma diferença entre homens e mulheres, evidenciando um percentual de 52,2\% empreendedores do gênero feminino, contra 47,8\% empreendedores do gênero masculino. Machado (2012) reforça a capacidade que a mulher tem de se adequar a multifunções. Strobino et al. (2014) considera ainda que são exceções as empreendedoras que tem a divisão entre trabalho e vida pessoal bem estabelecida. Desse modo, é comum o conflito entre trabalho e família.

Os autores Teixeira et al. (2016) relataram em pesquisa que as mulheres escolheram pela atividade empreendedora em razão da capacidade de autonomia e flexibilidade e por aspectos motivacionais pela busca constante em conciliar família e trabalho. São muitas as características necessárias que definem o retrato de uma gestora eficaz de uma determinada organização. Dornelas (2014) assemelha essas características a empreendedores que por sua vez apresentam afeição inovadora e selecionam oportunidades. Segundo Mattos et al. (2005), o avanço da tecnologia é um dos principais fatores para o aumento da competitividade no mercado empreendedor, onde cabe aos empreendedores estarem sempre em busca de qualidade e competência, pois é o que garante a sobrevivência ou a extinção das organizações. O uso de técnicas de gestão pode elevar a organização aumentando sua competência e melhorando o seu desempenho para possa atingir a qualidade, e isso só será possível por meio da escolha da ferramenta que melhor irá se adequar ao planejamento estratégico da organização (SILVEIRA et al., 2016).

Como técnica de gestão, o modelo de bricolagem foi utilizado pela primeira vez por Lévi-Strauss (1997), que intitulava a teoria como uma mágica que o ambiente sofria ao fazer uso dessa teoria. Este método foi apresentado em sua obra, pensamento selvagem (pensée sauvage), na qual ressalta que este modelo tem um pensamento mitológico com características que permitem expressar algo associado de um repertório cuja combinação é variada (SOUZA et al., 2016). No ano de 2005, o método bricolagem aparece como uma 
nova perspectiva na literatura de empreendedorismo, apresentado pelos autores Ted Baker e Reed Nelson, voltado para a análise dos tipos ou níveis de comportamento que despertam entre empreendedores que deparam com ambiente de grande limitação de recursos (BARROS, 2016).

Baker et al. (2005) definem a modelo bricolagem como uma combinação de recursos disponíveis com o intuito de resolver os problemas e identificar oportunidades. No momento em que engenheiros centralizam na forma de agrupar ferramentas e materiais para um determinado projeto, o método bricolagem ao contrário disso utiliza apenas os materiais que já estão disponíveis (FISHER, 2012). Na bricolagem não se usa encontrar certezas, como se elas ficassem escondidas ao aguardo de um pesquisador. O objetivo é compreender a sua estruturação e levantar questionamentos como os variados autores sociais formulam e reformulam o que é cobrado pelos argumentos influenciadores (NEIRA et al., 2012). Apesar de sua complexidade, produzir bricolagem demanda definição de métodos, procedimentos e referenciais. Nos princípios de Denzin et al. (2006) o bricoleur é "um indivíduo que confecciona colchas [...] que utiliza as ferramentas estéticas e materiais do seu ofício, empregando efetivamente quaisquer estratégias, métodos ou materiais empíricos que estejam ao seu alcance". De acordo com as pesquisas de Barros (2016), o termo Bricolagem se caracteriza por três elementos fundamentais, conforme Quadro 2.

Quadro 2: Elementos do método de bricolagem

\begin{tabular}{|l|l|}
\hline $\begin{array}{l}\text { Recursos } \\
\text { Disponíveis }\end{array}$ & $\begin{array}{l}\text { São entendidos como recursos que o empreendedor tem em mãos naquele exato momento de } \\
\text { necessidade, que podem ser recursos de variados como resíduos, frações de algum projeto, objetos e até } \\
\text { mesmo contatos sociais. }\end{array}$ \\
\hline Recombinação & $\begin{array}{l}\text { O empreendedor se adapta a situação e reinventa algo por meio de métodos engenhosos com os recursos } \\
\text { que tem em mãos e atribui novas funções a esses recursos. }\end{array}$ \\
\hline Fazer acontecer & $\begin{array}{l}\text { Isto é não apenas fazer a transformação dos recursos, mas sim utilizá-los de maneira correta, sem se } \\
\text { preocupar com as especulações se o método é correto ou não, uma vez essa ação ocorre de forma } \\
\text { experimental, sendo uma fase desafiadora ao empreendedor. }\end{array}$ \\
\hline
\end{tabular}

Fonte: adaptado de Barros (2016).

Baker et al. (2005) consideram que o método de Bricolagem se especifica "ao fazer acontecer através da aplicação de combinações dos recursos disponíveis a novos problemas e oportunidades". Desse modo, permite a ideia de que o método é vantajoso, uma vez que se utiliza de recursos disponíveis à mão e que ao se deparar com uma situação de escassez de recursos o empreendedor consegue tornar o que não era útil em algo totalmente útil e que lhe permite criar e contemplar uma possível oportunidade. Em contraponto, Barros (2016) adverte que o método Bricolagem é utilizado como um processo experimental, não sabendo ao certo se a utilização de recursos escassos que se transformam em algo totalmente novo possa trazer a solução para o problema. O que pode confirmar de imediato é que o empreendedor deve ter características que advenha da construção de novos cenários e transformá-los em algo positivo para sua organização, conforme demonstrado na figura 1.

O processo de Bricolagem oferta ao empreendedor indicações em relação aos prováveis caminhos a serem seguidos. Importante salientar que a análise do empreendedor em um ambiente de recursos escassos pode orientá-lo não somente na busca em enfrentar problemas advindos da crise financeira do Brasil, mas também torná-lo preciso na habilidade que irá adquirir ao dominar obstáculos e fortificar o campo empreendedor nacional (FISHER, 2012). Enquanto indivíduo, o empreendedor manifesta diversas 
características que o torna diferente, e assim o identifica. De acordo com Marinho (2016), essa identificação se dá por meio de habilidades que se aproximam muito da sua forma de ser e da maneira que transmite o seu ser aos outros.

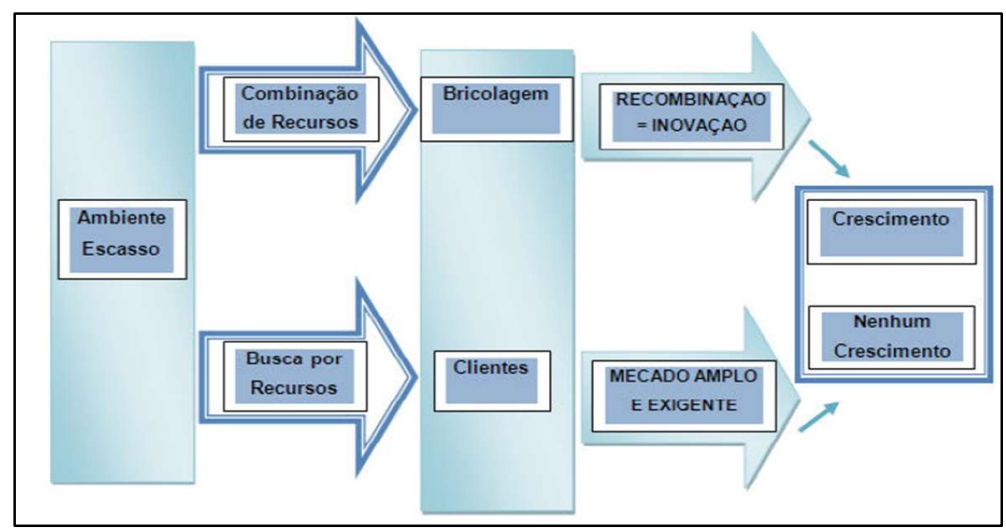

Figura 1: Método de Bricolagem. Fonte: adaptado de Fisher (2012).

McClelland (1985) afirma que o indivíduo precisa de necessidades motivadoras, sendo estas divididas em três conjuntos: (i) realização; (ii) afiliação/planejamento; e (iii) poder. Tais necessidades independem de gênero, cultura e até mesmo idade. Esta ordem é devida uma vez que o desejo de realização do empreendedor se baseia na primeira necessidade quando entra em evidência a aceitação de suas habilidades (BARTEL, 2010). A afiliação representa a necessidade de aproximar e manter a relação com as pessoas, o que se resulta na capacidade de planejar soluções frente às dificuldades dessas relações (McCLELLAND, 1985). O poder tem ligação em exercer a hierarquia e poder sobre os outros. Considerar as características empreendedoras é ter a visão voltada para contribuir com o desenvolvimento econômico e social, o que explica a relevância dessas características, devendo ser estas estarem sempre em desenvolvimento (RAUPP et al., 2011). De certo modo, as principais características empreendedoras devem estar sempre em desenvolvimento, conforme Quadro 3.

Quadro 3: Características empreendedoras

\begin{tabular}{|c|c|}
\hline Características & Comportamento \\
\hline $\begin{array}{l}\text { Busca de oportunidades e } \\
\text { iniciativa }\end{array}$ & Faz as coisas antes de solicitado, aproveita oportunidades para começar um negócio. \\
\hline Correr riscos calculados & Avalia alternativa e calcula riscos; age para reduzir os riscos ou controlar os resultados. \\
\hline Persistência & $\begin{array}{l}\text { Age repetidamente ou muda de estratégia, a fim de enfrentar um desafio ou superar um } \\
\text { obstáculo. }\end{array}$ \\
\hline $\begin{array}{l}\text { Exigência de qualidade e } \\
\text { eficiência }\end{array}$ & $\begin{array}{l}\text { Encontra maneiras de fazer as coisas melhor, mais rápido ou mais barato; age de modo a } \\
\text { fazer coisas que satisfazem ou excedem padrões de excelência. }\end{array}$ \\
\hline Comprometimento & $\begin{array}{l}\text { Assume responsabilidade pessoal pelo desempenho necessário ao atingimento de metas e } \\
\text { objetivos. }\end{array}$ \\
\hline Busca de informações & Investiga pessoalmente como fabricar um produto ou fornecer um serviço. \\
\hline Estabelecimento de metas & $\begin{array}{l}\text { Define metas de longo prazo, claras e específicas; e estabelece objetivos mensuráveis e de } \\
\text { curto prazo. }\end{array}$ \\
\hline $\begin{array}{l}\text { Planejamento e monitoramento } \\
\text { sistemáticos }\end{array}$ & $\begin{array}{l}\text { Planeja dividindo tarefas de grande porte em sub tarefas com prazos definidos; mantém } \\
\text { registros financeiros e utiliza-os para tomar decisões. }\end{array}$ \\
\hline Persuasão e redes de Contato & Utiliza pessoas chave como agentes para atingir seus próprios objetivos. \\
\hline Independência e autoconfiança & $\begin{array}{l}\text { Busca autonomia em relação a normas e controles de outros; expressa confiança na sua } \\
\text { própria capacidade de completar uma tarefa difícil ou de enfrentar um desafio. }\end{array}$ \\
\hline
\end{tabular}

Fonte: adaptado de Minello et al. (2017).

Para analisar o comportamento empreendedor, McClelland (1985) fez uso da abordagem 
quantitativa, na qual percebeu a necessidade de isolar do perfil empreendedor as características psicológicas e culturais (BOAVA et al., 2006). As características comportamentais empreendedoras (CCEs) de McClelland estão associadas ás personalidades de empreendedores bem-sucedidos: conhecer muito bem o ramo de atuação, ser agressivo (gostar de desafios), corajoso, autocrítica, capacidade de aprendizagem, ter valor para a sociedade, ser paciente, ser polivalente (proativo), ter flexibilidade, administrar o tempo, obter e organizar os recursos necessários, comportamento ético (OLIVEIRA et al., 2014).

\section{METODOLOGIA}

A presente pesquisa fez uso do rigor metodológico, utilizando-se da pesquisa básica, explicativa e exploratória. Quanto a sua natureza a pesquisa é básica, que segundo Gil (2010) tem a intenção de agrupar estudos que tem como objetivo completar espaços que detém o conhecimento. Quanto aos objetivos esta pesquisa é explicativa, pois, de acordo com Gil (2010), atenta-se em identificar os aspectos que especificam ou colaboram para a ocorrência de fenômenos. A pesquisa ainda pode ser considerada como exploratória, pois tem a intenção de proporcionar um entendimento a cerca de determinados fatos, esclarecendo questões que possam estar superficialmente entendidas sobre um determinado assunto (GIL, 2010). Para a pesquisa de "cunho exploratório", a abordagem quantitativa é a mais indicada (GODOY, 2005). Essa pesquisa, preocupa-se com o tratamento dos dados, empregando quantificação, tanto na coleta de informações, quanto na análise delas, por meio de técnicas estatísticas, que vão desde a mais simples até a mais complexa (MALHOTRA, 2006).

Esta pesquisa teve como objetivo de análise empreendedoras das cidades de Coronel Murta e Araçuaí, situadas na região do vale do Jequitinhonha. Para a escolha das empreendedoras foi adotado os seguintes critérios de amostragem: sexo feminino e ramo empresarial diferentes. Para atingir os critérios exigidos, foram encontradas doze empreendedoras, sendo dez da cidade de Coronel Murta e duas da cidade de Araçuaí. A diferença de quantidade de empreendedoras se dá por critérios de acessibilidade. 0 Quadro 4 caracteriza os participantes da pesquisa.

Quadro 4: Quantitativo de participantes seus respectivos ramos empresariais.

\begin{tabular}{|l|l|l|l|l|}
\hline Participante & Ramo Empresarial & Cidade & Tempo de Atuação & Escolaridade \\
\hline 1 & Mercearia & Coronel Murta & 9 meses & Ensino Médio \\
\hline 2 & Lanchonete & Coronel Murta & 3 anos & Superior completo \\
\hline 3 & Loja de Vestuário & Coronel Murta & 2 anos & Ensino Médio \\
\hline 4 & Restaurante & Coronel Murta & 8 anos & Ensino Médio \\
\hline 5 & Consultório Odontológico & Coronel Murta & 4 anos & Superior completo \\
\hline 6 & Lembrancinhas e Decoração de Festas & Coronel Murta & 13 anos & Ensino Médio \\
\hline 7 & Salão de Beleza & Coronel Murta & 2 anos & Ensino Médio \\
\hline 8 & Corte e Costura & Coronel Murta & 4 anos & Ensino Médio \\
\hline 9 & Boleira & Coronel Murta & 12 anos & Ensino Médio \\
\hline 10 & Farmácia & Coronel Murta & 3 anos & Superior completo \\
\hline 11 & Doceria e Salgaderia Artesanal & Araçuaí & 4 anos & Ensino Médio \\
\hline 12 & Academia & Araçuaí & 7 anos & Superior completo \\
\hline
\end{tabular}

Após definidos os métodos que fundamentam a pesquisa, se faz necessário estabelecer os instrumentos de coleta de informações, que possibilitarão a obtenção de dados pertinentes e fundamentais para a continuidade do trabalho. Para a análise dos resultados foi empregado como instrumento de pesquisa 
o questionário. Para atingir o objetivo proposto os questionários foram realizados com perguntas estruturadas sobre as seguintes dimensões: Características comportamentais empreendedoras de Baker e Nelson e as Características comportamentais empreendedoras de McClelland. Este tipo de instrumento de pesquisa pode conter respostas fechadas e/ou abertas, as fechadas facilitam a análise e tabulação dos dados, as abertas possibilitam respostas mais detalhadas e ricas em informações (CERVO et al., 2007).

\section{RESULTADOS E DISCUSSÃO}

As ferramentas de gestão empreendedora não foram colocadas de forma clara para as empreendedoras pesquisadas, mas isso não impossibilitou fazer uma análise em relação ao uso de ferramentas. Diante das respostas em relação as categorias comportamentais empreendedoras de Baker e Nelson, observou-se que, de forma empírica, o modelo de bricolagem é utilizado pelas empreendedoras que responderam nos questionários que utilizaram de recursos disponíveis para abrir o seu empreendimento o que serviu de motivação e utilizaram também a recombinação de recursos que possuíam sem buscar outros que já não possuíam. Na Figura 2 é possível observar que 55\% das empreendedoras iniciaram o seu negócio com recursos que já possuíam, houve um planejamento e motivação para empreender e que as mesmas têm uma percepção sobre o ambiente interno e externo de seu empreendimento. Cerca de $35 \%$ das empreendedoras concordaram parcialmente com o contexto apresentado. Tanto para discordância total ou parcial para esta categoria somaram $10 \%$.

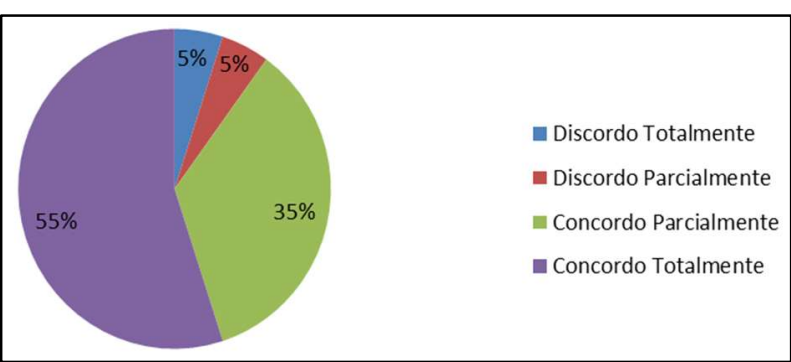

Figura 2: Categoria Recursos Disponíveis.

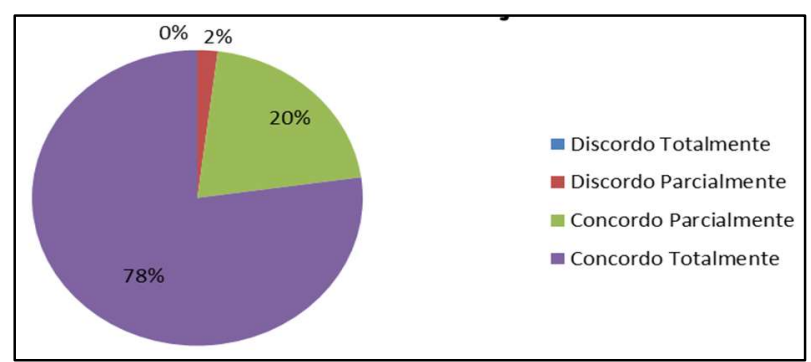

Figura 3: Categoria Recombinação.

Embora tenha sido detectado que as empreendedoras possuem Cadastro Nacional de Pessoa Jurídica (CNPJ) e atuam diretamente em seu ramo empresarial, é possível notar que, as que estão no mercado há mais tempo não possui nenhuma formação superior e uma delas que tem formação na atua na área, sendo seu ramo empreendedor não totalmente direcionado a sua formação. Isto deixa em evidência que o empreendedorismo surgiu tanto pela oportunidade, quanto pela necessidade. Para esta segunda questão, houve uma discrepância em relação ao nível de concordância, pois 78\% das empreendedoras fizeram algum tipo de adaptação em seu empreendimento, utilizando a recombinação de recursos, levando em consideração a sua experiência como empreendedora, os valores organizacionais que a empresa possui. Conforme Figura 3, 20\% das pesquisadas concordam parcialmente com as perguntas dessa categoria, e o nível de discordância somam $2 \%$.

Para verificar esta terceira e última categoria referente ao questionário de Baker e Nelson, faz necessário salientar como o tema empreendedorismo é retratado. Essas empreendedoras assumem riscos 
financeiros, mas mantém a disciplina em termos de manter o produto e/ou serviço sempre de qualidade para atender o cliente. A Figura 4 apresenta a análise das empreendedoras segundo o nível de concordância que foi bastante significativo em relação ao fazer acontecer, somando $98 \%$. Considera que ter uma visão empreendedora é necessário ter iniciativa, criatividade, comprometimento, independência, autoconfiança e inovação, sendo que estas competências importantes para abertura do seu empreendimento e para manter o seu negócio no mercado competitivo.

Com relação às características comportamentais empreendedoras de McClelland, apresenta para as empreendedoras, alguns perfis que cada uma pode enxergar em si mesma. Sendo que, $59 \%$ concordaram totalmente, $39 \%$ concordaram parcialmente e os níveis de discordância somaram $2 \%$. O que se observa é que estas empreendedoras se engajaram em ter negócio, deixando em evidência a concretização e realização do seu desejo de ter uma empresa.

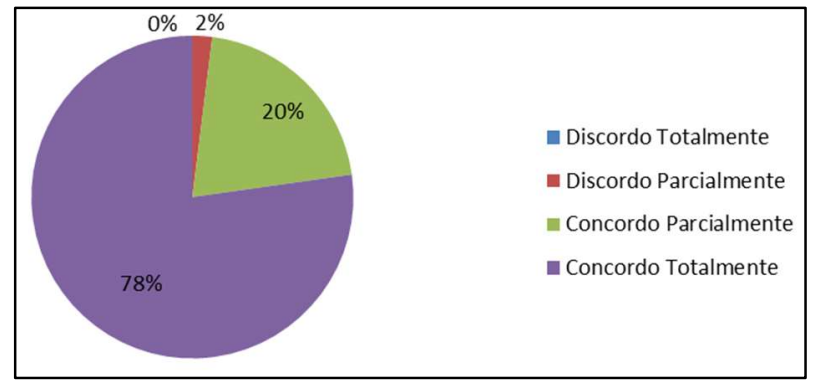

Figura 4: Categoria fazer acontecer.

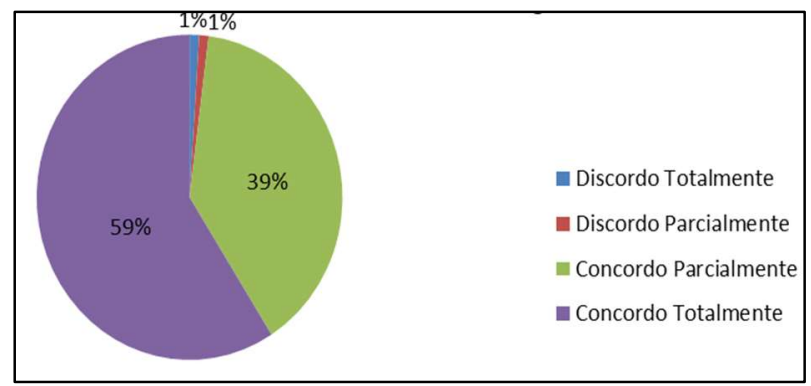

Figura 5: Categoria desejo de realização.

Na etapa de planejamento, percebe-se o uso de ferramentas, pois foi positivo o nível de concordância em relação ao planejamento, estabelecimento de metas, monitoramento e a busca pela satisfação do cliente. Este gráfico faz a representação das respostas sobre a segunda categoria relacionada às CCEs de McClelland. Sendo que o nível de concordância entre as empreendedoras somam 96\% para os riscos calculados em situações diversas, tem sempre metas estabelecidas tanto a longo como em curto prazo. Busca por informações e cursos para atender seus clientes da melhor forma, e dentro de sua organização procura não centralizar as tarefas, revisa os planos e registra as finanças para ter um auxílio para as tomadas de decisões. O nível de discordância para esta categoria somou-se $4 \%$.

Outro fator importante destacado na Figura 6 é o fato de que este estudo traz em tona a certificação dos relatos de Gouvêa et al. (2013), onde retratam que a introdução da mulher no mercado de trabalho se deu de forma lenta e foi ganhando espaço aos poucos, superando obstáculos e impasses no decorrer dos anos. Tendo como parâmetro a discrepância de anos em relação ao tempo que o ramo empresarial das pesquisadas estão no mercado, pode-se ter um ideia de como este cenário foi mudando. Atualmente o número de empreendimentos abertos por mulheres é maior, não sendo a mesorregião do vale do Jequitinhonha fora das estatísticas. $O$ empreendedorismo feminino permite a este gênero se conhecer em sua multi tarefas. Este estudo possibilitou identificar em mulheres, mães, esposas com perfis que são diferenciados na sociedade em que estão inseridas.

Machado (2012) enfatiza a capacidade que a mulher tem de se adentrar no ramo empreendedor, e ter bem estabelecida a sua relação de vida pessoal e profissional. As análises às respostas permitem entender 
este contexto, uma vez que, são empreendedoras motivadas pela busca da flexibilidade em conciliar profissional e família. Para esta terceira e última categoria, analisada na Figura 7, o que se pôde analisar é que não houve nível de discordância em relação às perguntas, sendo o nível de concordância bastante representativo com a soma de $100 \%$. O que as empreendedoras concordaram por unanimidade foi em relação à rede de contatos que são fundamentais para o seu empreendimento, as relações comerciais e o comprometimento no que tange a satisfação do seu cliente.

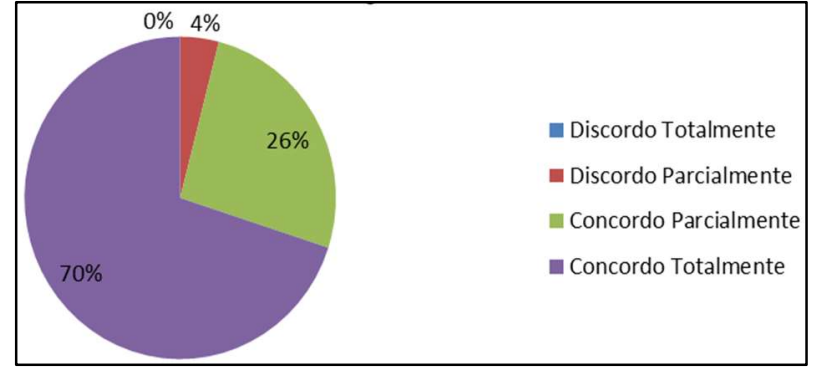

Figura 6: Categoria planejamento e resolução de problemas.

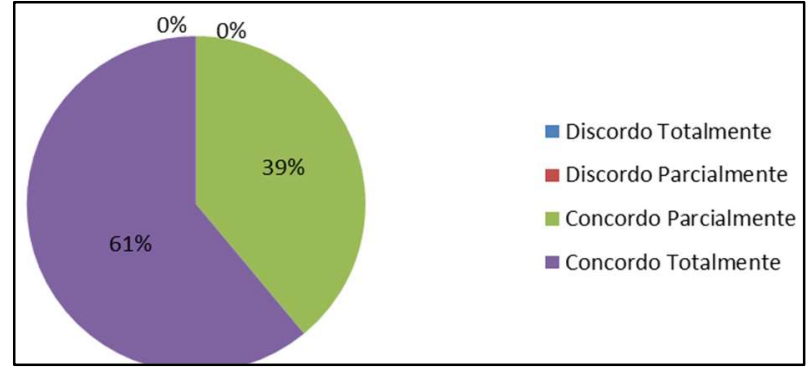

Figura 7: Categoria influência.

\section{CONCLUSÕES}

Ao considerar que o ramo do empreendedorismo é o que mais cresce no Brasil, o gênero feminino está cada vez mais ganhando destaque, o que se faz relevante estudos que contribuam para o aprofundamento da discussão. São muitos os fatores que inibem e facilitam a entrada das mulheres para o mercado dos negócios. O contexto histórico para a mulher ganhar o seu espaço neste cenário se deu de forma lenta, mas não de impossibilidades. Isso se confirma nesta pesquisa que, buscou para responder os questionários ramos empresariais que tivessem como empreendedoras e donas de negócios, apenas mulheres. $O$ que entra em destaque também é que entre as 12 pesquisadas não existe igualdade entre o ramo empreendedor que cada uma atua.

Os resultados deste estudo apontam que foi possível relacionar as teorias de Baker e Nelson e de McClelland com os perfis das empreendedoras pesquisadas. A escala likert permitiu analisar de forma clara e objetiva o entendimento das empreendedoras em relação às teorias de Baker e Nelson, quando entram em conformidade com o mercado que o seu negócio está inserido, o que as motivaram a iniciar o negócio, o que tinham de imediato e a percepção que tem em relação ao ambiente interno e externo de seu negócio. As teorias de McClelland permitiram as empreendedoras se identificarem não somente com o seu negócio, mas também consigo mesmas.

Foram utilizadas as compreensões de Baker e Nelson em relação ao modelo de Bricolagem. A cidade de Coronel Murta se encontra em um contexto onde as empreendedoras precisam gerir o seu negócio mediante recursos escassos e levando em consideração não somente o mercado competitivo da cidade em que seu empreendimento está inserido, mas também o mercado da cidade limítrofe, que é Araçuaí. Este método de Bricolagem vem de encontro para analisar quais os recursos que faltam para as empreendedoras e de que forma elas podem planejar e buscar motivação para driblar a concorrência e manter seus clientes. Para o mercado competitivo de Coronel Murta as vantagens deste método são bem apresentadas, uma vez 
que o cenário é de recursos escassos, e as empreendedoras têm buscado pelas recombinações de recursos para se manterem no mercado. Para a cidade de Araçuaí, não foi possível fazer essa análise levando em consideração o quantitativo de empreendedoras pesquisadas.

Em relação à pergunta que norteou esta pesquisa sobre as características comportamentais empreendedoras de Baker e Nelson e de McClelland, quais delas podem ser diretamente relacionados com os perfis de empreendedoras residentes da mesorregião do Vale do Jequitinhonha, foi possível identificar no perfil das pesquisadas que se pode fazer uma relação às CCEs de Baker e Nelson e McClelland. Foi identificado que as respondentes desta pesquisa têm entendimento acerca do tema, no entanto, não conseguem percebê-las em seu cotidiano mediante o seu empreendimento. Todo conhecimento adquirido pelas pesquisadas que envolve o seu negócio foram desenvolvidos mediantes alguns cursos, mas principalmente á experiência vivenciada.

As contribuições que este estudo poderá a vir proporcionar, advém dos cenários econômicos que os empreendimentos em estudo estão inseridos, dos perfis relatados na teoria e relacionados com as pesquisadas. Para a comunidade científica e para a academia, esta pesquisa poderá vir a contribuir para aprofundar a investigação sobre perfis empreendedores, que envolvam fatores inibidores e facilitadores para transmissão do conhecimento. A própria estratégia de pesquisa, pauta a sua limitação, pois envolve um quantitativo que atinge apenas ramos empresarias distintos, sem abranger igualdades de ramos. Por fim, este estudo proporcionou desenvolvimento em relação á conhecimento para os autores acerca do tema empreendedorismo feminino, sendo isto possível por envolver estudo bibliográfico e análises dos dados relacionados à pesquisa.

\section{REFERÊNCIAS}

ALMEIDA, F. M.; VALADARES, J. L.; SEDIYAMA, G. A. S.. A Contribuição do Empreendedorismo para o Crescimento Econômico dos Estados Brasileiros. Revista de Empreendedorismo e Gestão de Pequenas Empresas, v.6, n.3, p.466-494, 2017

BAKER, T.; NELSON, R.. Creating something from nothing: Resource Construction through entrepreneurial Bricolage. Administrative Science Quarterly, v.50, n.3, p.329-366, 2005.

BARROS, M.. Empreendedorismo e Educação Empreendedora. Revista Fatec SEBRAE em Debate: Gestão, Tecnologia e Negócios, v.2, n.3, 2016.

BARTEL, G.. Análise da evolução das características comportamentais empreendedoras dos acadêmicos do curso de administração de uma IES catarinense. Dissertação (Mestrado) - Universidade Regional de Blumenau, Blumenau, 2010.

BOAVA, D. L. T.; MACEDO, F. M. F.. Estudo sobre a essência do empreendedorismo. In: ENCONTRO DA ASSOCIAÇÃO NACIONAL DE PÓS-GRADUAÇÃO E PESQUISA EM ADMINISTRAÇÃO. Anais. Salvador, 2006.
CANTILLON, R.. Essay on the nature of commerce in general. New Brunswick: Transaction Publishers, 1755.

CERVO, A. L.; BERVIAN, P. A.; SILVA, R.. Metodologia Científica. 6 ed. São Paulo: Pearson, 2007.

DAFT, R.. Administração. São Paulo: Cengage Leaming, 2015.

DENZIN, N. K.; LINCOLN, Y. S.. Planejamento da pesquisa qualitativa: teorias e abordagens. 2 ed. Porto Alegre: ARTMED, 2006.

DORNELAS, J. C. A.. Empreendedorismo: Transformando Ideias Em Negócios. 5 ed. Rio de Janeiro: LTC, 2014.

FISHER, G.. Effectuation, Causation, and Bricolage: A Behavioral Comparison of Emerging Theories in Entrepreneurship. Revista Entrepreneurship Theory and Practice, v.36, n.5, 2012.

GEM. Global Entrepreneurship Monitor. Relatório Executivo: Empreendedorismo no Brasil 2017. Curitiba: IBPQ, 2017.

GIL, A. C.. Como Elaborar Projetos de Pesquisa. 5 ed. São Paulo: Atlas, 2010 
GIMENEZ, F. A. P.; FERREIRA, J. M.; RAMOS, S. C.

Empreendedorismo Feminino no Brasil: Gênese e Formação de um Campo de Pesquisa. Revista de Empreendedorismo e Gestão de Pequenas Empresas, v.6, n.1, 2016.

GODOY, A. S.. Refletindo sobre critérios de qualidade da pesquisa qualitativa. Revista Eletrônica de Gestão Organizacional, v.3, n.2, p.80-89, 2005.

GOUVÊA, A. B. C. T.; SILVEIRA, A.; MACHADO, H. V.. Mulheres Empreendedoras: Compreensões do Empreendedorismo e do Exercício do Papel Desempenhado por Homens e Mulheres em Organizações. Revista de Empreendedorismo e Gestão de Pequenas Empresas, v.2, n.2, p.32-54, 2013.

LÉVI-STRAUSS, C.. Olhar, escutar, ler. São Paulo: Companhia das Letras, 1997.

MACHADO, F. B.. Dilemas de Mulheres Empreendedoras em Empresas Inovadoras Nascentes. In: ENCONTRO DA ASSOCIAÇÃO NACIONAL DE PÓS-GRADUAÇÃO E PESQUISA EM ADMINISTRAÇÃO. Anais. Rio de Janeiro: ANPAD, 2012.

MALHOTRA, N.. Pesquisa de Marketing: uma orientação aplicada. 4 ed. São Paulo: Prentice Hall, 2006.

MARINHO, E. S.. Processo de incubação, características empreendedoras e aprendizagem empreendedora: uma perspectiva interativa. Dissertação (Mestrado em Gestão de Organizações Públicas) - Universidade Federal de Santa Maria, Santa Maria, 2016.

MATTOS, J. R. L.; GUIMARÃES, L. S.. Gestão da tecnologia e inovação: uma abordagem prática. São Paulo: Saraiva, 2005.

MCCLELLAND, D. C.. Characteristics of successful entrepreneurs. The Journal of Creative Behavior, v.21, n.3, p.219-233, 1985.

MELO, M. B.. Cultura Empreendedora na Universidade Federal de Santa Catarina: O Centro Tecnológico como Espaço de Práticas Empreendedoras. Dissertação (Mestrado) - Universidade Tecnológica Federal do Paraná, Pato Branco, 2014.

MINELLO, I. F.; BÜRGER, R. E.; KRÜGER, C.. Características comportamentais empreendedoras: um estudo com acadêmicos de administração de uma universidade Brasileira. Revista de Administração, Santa Maria, v.10, 2017.

NEIRA, M. G.; LIPPI, B. G.. Tecendo a Colcha de Retalhos: a bricolagem como alternativa para a pesquisa educacional. Revista Educação \& Realidade, v.37, n.2, p.607-625, 2012.

OLIVEIRA, J. R. C.; SILVA, W. A. C.; ARAÚJO, E. A. T.. Características comportamentais empreendedoras em proprietários de MPES Longevas do Vale do Mucuri e Jequitinhonha/MG. Revista de Administração Mackenzie, São Paulo, v.15, n.5, p.102-139, 2014. DOI: https://doi.org/10.1590/167869712014/administracao.v15n5p102-139

RAUPP, M. A.; BAUREN, I. M.. Perfil do suporte oferecido pelas incubadoras brasileiras às empresas incubadas. Revista Eletrônica de Administração de Porto Alegre, Porto Alegre, v.17, n.2, 2011. DOI: https://doi.org/10.1590/S1413$\underline{23112011000200002}$

RODRIGUES, R. B.; MELO, M. C. O. L.; LOPES, A. L. M.. Gênero Feminino no Empreendedorismo de Sucesso em Minas Gerais: Estudo de Casos. Revista Organizações em Contexto, São Bernardo do Campo, v.12, n.23, p.143-172, 2016.

SAY, J. B.. Tratado de Economia Política. São Paulo: Paris, 1815.

SCHUMPETER, J. A.. The creative response in economic history. Journal of Economic History, v.7, n.2, p.149-159, 1947.

SILVEIRA, H. E.; MARTELI, R.; OLIVEIRA, V. V.. A Implantação da Ferramenta 5w2h como Auxiliar no Controle da Gestão da Empresa Agropecuária São José. Revista de Administração do Sul do Pará, v.3, n.2, p.68-80, 2016.

SOUZA, W. L.; SILVA, A. A.; ALVES, D. C. S.; ROCHA, C. C.; MELO, T.. O Bricoleur, uma clínica rizomática e o 'fazer psi': repensando as práticas psicológicas. Periódico Caderno de Graduação, Ciências Humanas e Sociais, Maceió, v.3, n.2, p.323-382, 2016

STROBINO, M. R. C.; TEIXEIRA, R. M.. Empreendedorismo Feminino e o Conflito Trabalho-Família: Estudo de Multicasos no Setor da Construção Civil da Cidade de Curitiba. Revista de Administração, São Paulo, v.49, n.1, p.59-76, 2014. DOI: https://doi.org/10.5700/rausp1131

TEIXEIRA, R. M.; BOMFIM, L. C. S.. Empreendedorismo feminino e os desafios enfrentados pelas empreendedoras para conciliar os conflitos trabalho e família: estudo de casos múltiplos em agências de viagens. Revista Brasileira de Pesquisa em Turismo, São Paulo, v.10, n.1, p.44-64, 2016. DOI: https://doi.org/10.7784/rbtur.v10i1.855

VALE, G. M. V.; CORRÊA, V. S.; REIS, R. F.. Motivações para o Empreendedorismo: Necessidade Versus oportunidade? Revista de Administração Contemporânea, v.18, n.3, p.311327, 2014.

VERGA, E.; SILVA, L. F. S.. Empreendedorismo: Evolução Histórica, Definições e Abordagens. Revista de Empreendedorismo e Gestão de Pequenas Empresas, v.3, n.3, p.3-30, 2014. DOI: http://dx.doi.org/10.14211/regepe.v3i3.161

ZEN, A. C.; FRACASSO, E. M.. Quem é o empreendedor: as implicações de três revoluções tecnológicas na construção do termo empreendedor. Revista de Administração Mackenzie, v.9, n.8, p.135-150, 2008. DOI: http://dx.doi.org/10.1590/S1678-69712008000800008

A CBPC - Companhia Brasileira de Produção Científica (CNPJ: 11.221.422/0001-03) detém os direitos materiais desta publicação. Os direitos referem-se à publicação do trabalho em qualquer parte do mundo, incluindo os direitos às renovacões, expansões e disseminações da contribuicão, bem como outros direitos subsidiários. Todos os trabalhos publicados eletronicamente poderão preservam os direitos autorais, mas não têm permissão para a publicação da contribuição em outro meio, impresso ou digital, em português ou em tradução. 